$\begin{array}{ll} & \begin{array}{l}\text { Kastamonu Eğitim Dergisi } \\ \text { Kastamonu Education Journal }\end{array} \\ \begin{array}{l}\text { Ocak 2019 Cilt:27 Sayı:1 } \\ \text { kefdergi.kastamonu.edu.tr }\end{array} & \text { Başuru Tarihi/Received: } 18.09 .2017 \\ \text { Kabul Tarihi/Accepted: } 22.02 .2018\end{array}$

\title{
Fen Lisesi Öğrencilerinin Fizik Dersine Yönelik Tutumları İle Akademik Benlik Tasarımlarının İncelenmesi
}

\section{Examination of Science High School Students' Attitudes and Academic Self-Concepts towards the Physics Course}

\section{Öz}

\author{
Hülya PEHLIVAN ${ }^{1}$
}

Bu araştırmanın amacı Ankara Fen Lisesi öğrencilerinin Fizik dersine yönelik tutumlarıyla akademik benlik tasarımlarını a) cinsiyet, b) sınıf düzeyi, c) başarı düzeyi, d) öğrenim görmeyi planladığı fakülte bazında incelemektir. Veri elde etmek amacıyla bir adet fizik dersine yönelik tutum ölçeği ile bir adet akademik benlik tasarımı ölçeği kullanılmıştır, ölçekler Ankara Fen Lisesinde öğrenim gören toplam 339 öğrenciye uygulanmıştr. Veri elde etmek amacıyla bir adet fizik dersine yönelik tutum ölçeği ile bir adet akademik benlik tasarımı ölçeği kullanılmıştr. 34 madden oluşan fizik dersine yönelik tutum ölçeğinin güvenirliği 0.96 olarak bulunurken, 8 maddeden oluşan akademik benlik tasarımının güvenirliği ise 0.80 olarak bulunmuştur. Araştırmadan elde edilen sonuçlara göre, Fen Lisesi öğrencilerin fizik dersine yönelik tutumları erkek öğrenciler lehine değişmektedir. Yine, öğrencilerin fizik dersine yönelik tutumları ile akademik benlik tasarımlarının sınıf düzeyi, başarı düzeyi ve öğrenim görmeyi planladıkları fakülteye göre anlamlı farklııklar olduğu bulunmuştur.

Anahtar Kelimeler: Fen lisesi, fizik dersi, tutum, fizik dersine yönelik tutum

\section{Abstract}

The purpose of the research is to investigate the students' attitudes' and academic self-concepts with a) gender, b) class level, c) level of success and d) the faculty they plan to study towards Physics course of Ankara Science High School. The attitude scale about the physics course and academic self-concept scales were used in order to collect data, the scales were applied to totally 339 students in Ankara Science High School. An attitude scale about the physics course and an academic self-concept scale were used in order to collect data. While the reliability rate of Attitude Scale for Physics Course comprised of 34 items was found as 0.96 , the reliability rate of academic self-concept comprised of 8 items was found as 0.80 . According to the results obtained from the research, attitudes of Science High School students towards the physics course were found to be in favor of male students. In addition, significant differences were found in attitudes and academic self-concepts of the students towards the physics course based on class level, success level and the faculty they plan to study.

Keywords: Science High School, physics course, attitude, attitude towards the physics course.

1. Hacettepe Üniversitesi, Eğitim Fakültesi, Eğitim Bilimleri Bölümü, Ankara, Türkiye; https://orcid.org/0000-0001-6772-8125 


\section{Extended Abstract}

Purpose of study: It is a well-known fact that it is necessary to keep up with the developments in science and technology so as to ensure the development of the country. Among the primary duties of science education are to develop skills of individuals to invent, think and evaluate, to constitute compatible labor force and to bring in skills leading way to the modern technology. Physics education takes a crucial part in this field. Physics is a natural science examining the matter and mutual influences of matter and energy (Ertaş, 1993; Gök and Sılay, 2008). In other words, physics is a basic discipline based on experimental observations and quantitative measurements pertaining to understanding the natural events in our universe (Aycan and Yumuşak, 2002). Since it allows to understand the factors bringing about the natural events and to comprehend the societies undergoing gradually increasing technological changes, the physics constitutes an important basis in the field of science (Wambugu and Changeiywo, 2008). Physics education besides basic sciences education is attached great importance so as to follow extraordinary advances in today's technology. Since the source of all natural sciences is physics and all of the engineering disciplines use the physics, physics is regarded as an important field of study. Most important purpose of physics course, should be to enable students to develop positive attitudes towards the physics. Having a positive thought for physics course, refers to both loving physics and feeling oneself good about the capacity of coping with the situations containing physics knowledge (Leder, 1992). Having a positive thought for physics course, refers to both loving physics and feeling oneself good about the capacity of coping with the situations containing physics knowledge (Leder, 1992). Within this conceptual scope, in this study, attitudes and academic self-concepts of students, expected to contribute to the purpose of producing science and technology, towards physics lesson, which is one of the basic disciplines, were examined, and answers were sought for the following questions;

- Do attitudes and academic self-concepts of Science High School students towards physics course differ according to the gender?

- Do attitudes and academic self-concepts of Science High School students towards physics course differ according to the class level?

- Do attitudes and academic self-concepts of Science High School students towards physics course differ according to the success level?

- Do attitudes and academic self-concepts of Science High School students towards physics course differ according to the faculty they plan to study?

Method: It is a "descriptive" research aiming at revealing science high school students' attitudes and academic self-concepts towards physics course in terms of various variables. This research was conducted on a total of 339 students, 99 of whom were female and 240 of whom were male, studying in Ankara Science High School. Pre-application was conducted in Kırklareli Science High School to see the validity of the scales. 159 science high school students took part in the piloting. Piloting was conducted in November, 2008; and the real application was conducted in March, 2009. An attitude scale and academic self-concept scale about physics lesson were used as data collection instrument in this research. Attitude scale about physics course, used in this study was developed by the researcher by the help of similar scales. In this study, academic self-concept scale comprising of eight articles developed by Brookover et al (1964) was used. It was stated that reliability of this scale adapted to Turkish by Senemoğlu was found as $0.80,0.84$ and 0.89 in three different groups.

Finding and Discussion: This research was conducted in order to examine attitudes and academic self-concepts of science high school students towards the physics lesson based on a) gender, b) class level, c) success level and d) the faculty they plan to study. According to the results of the research conducted on 339 students studying in Ankara Science High School;

1) Attitudes of students studying in Ankara Science High School towards physics lesson differ according to the gender. The difference at the level of 0.01 is in favor of the male students. No difference resulting from gender was found in terms of academic self-concept relating to the physics lesson.

2) Attitudes of students studying in Ankara Science High School towards physics lesson differ according to the class level. The difference found at the level of 0.05 between 1st and 2 nd grade students was in favor of 1 st grade students; between 1st and 3rd grade students was in favor of 1st grade students; between 1st grade and 4th grade students was in favor of 1st grade students. Academic self-concepts of students studying in Ankara Science High School relating to the physics lesson differ. Difference found at the level of 0.05 between 1 st grade students and 4 th grade students is in favor of 1st grade students.

3) A difference at the level of 0.01 was found in terms of attitudes and academic self-concepts of students studying in Ankara Science High School towards physics lesson. The difference is in favor of those with good school levels.

4) Attitudes and academic self-concepts of students studying in Ankara Science High School towards physics lesson differ according to the faculty they plan to study. Considering the dimension of attitude, there is a significant difference at the level of 0.01 between those planning to study in engineering faculty and those planning to study in medical faculty in favor of the students planning to study in engineering study. Examining the dimension of academic self-concept, a significant difference at the level of 0.05 is seen between those planning to study in engineering faculty and those planning to study in medical faculty in favor of the students planning to study in engineering study, and between those planning to study in engineering faculty and those planning to study in other faculties in favor of the students planning to study in engineering study. 


\section{Giriş}

Ülkelerin kalkınması bilim ve teknolojideki gelişmelere ve ülke insanının bu gelişmelere ayak uydurabilmesine bă̆lıdır. Gerek ülkelerin gerekse bireylerin gelişmesi ve refaha ulaşması fen bilimlerindeki gelişmelerle sağlanabilir. Bilindiği üzere, bireylerin bilimsel buluş yapmaları, düşünme, irdeleme ve değerlendirme yetilerini kazanmaları, uyumlu bir işbirliği sağlayabilmeleri, çağın gerektirdiği teknolojiye uygun kritik beceriler kazanmaları fen bilimleri sayesinde olmaktadır. Fizik eğitimi ise gerek toplumsal gerekse bireysel anlamda bu alanda önemli hizmetler sunmaktadır.

Fizik doğayı anlamaya, doğal olayların neden ve sonuçlarını öğrenmeye ve bunları matematiksel yöntemlerle ifade etmeye yönelik bir doğa bilimidir ve madde, enerji ve maddenin karşılıklı etkilerini incelemeyi hedeflemektedir (Aycan ve Yumuşak, 2003; Ertaş, 1993; Gök, 2006; Gök ve Sılay,2008a ve Gök ve Sılay, 2008b). Fizik için evrenimizdeki doğal olayların anlaşılması amacını güden ve bu amacı gerçekleştirmek için deneysel gözlemler ve nicel ölçümleri işe koşan temel bir bilim dalı da denilebilir (Aycan ve Yumuşak, 2003). Fizik, doğal olaylara neden olan etkenleri inceleyerek ve insanlara ile toplumlara teknolojik değişmeler ve gelişmeler sunarak insanlığa önemli katkılar sağlamaktadır (Wambugu ve Changeiywo, 2008). Fizik, temel bir bilimdir ve çevremizde olan ya da olagelen bütün olaylarda fizik yasalarından ve ilkelerinden yararlanmak artk kaçınılmaz hale gelmiştir (Gök, 2006). Örneğin, fizik ilkelerini kullanan bilgisayarlar ve uydular yoluyla dünya küresel bir köye dönüşebilmekte, hastalıkları tanılama ve tedavide kullanılacak son teknolojiye uygun hızlı ve hassas araçların geliştirilmesiyle insanların kaliteli sağıı hizmeti almaları sağlanabilmekte ve hatta eğlence endüstrisinde özel bir etki yaratmak için fizik kurallarından yararlananılabilmektedir (Wambugu ve Changeiywo, 2008). Bu gelişmeler, günümüz koşullarında iyi bir fizik bilgisi gerektiren birçok meslek ortaya çıkmasına neden olmuştur. Mühendislik ise en çok fizik bilgisi gerektiren mesleklerin başında yer almaktadır ( Arandia, Zuza ve Guisasola, 2016).

Günümüz teknolojisindeki olağanüstü gelişmeleri takip edebilmek için temel bilimlerin öğretiminin yanı sıra fizik öğretimine de büyük önem verilmektedir. Örneğin, 1960'lı yıllarda Sovyetler Birliği'nin uzaya Sputnik adlı uzay aracını göndermesi ve İkinci Dünya Savaşı'nda Amerika'nın atom bombasını kullanmasıyla birlikte (Aslan, Ercan ve Tekbıyık, 2012) fizik dersi hem Sovyetler Birliği'nde hem ABD'de hem de gelişmiş ve gelişmekte olan diğer dünya ülkelerinde eğitim programları açısından önem kazanmıştır. Bunun yanı sıra, Mirzoyan (2005) fizik dersinin a) bilimsel-teknolojik ilerlemenin temeli olması ve b) felsefe ile güçlü bağlarının bulunması ve bu şekilde öğrencide bilimsel dünya görüsü oluşturması gibi nedenlerden dolayı Sovyetler birliği'nde eğitim programlarında önemli bir yer işgal ettiğini belirtmektedir. Fizik öğretimi, aynı zamanda, öğrencilere bilimsel araştırma için gerekli olan bilimsel bilgi ve becerileri kazandırmakta ve daha sonra bunları kullanarak toplumdaki düşük yaşam koşullarını iyileştirmek için ekonomik ve teknolojik katkıda bulunmaktadır (Wambugu ve Changeiywo, 2008).

Tüm doğa bilimlerinin kaynağııın fizik olması ve tüm mühendislik dallarının fizik kurallarını kullanması nedeniyle fizik önemli bir çalışma alanı olarak görülmektedir (Arandia, Zuza ve Guisasola, 2016). Ancak, bilindiği üzere, öğrenciler fizik dersini soyut ve zor bir ders olarak algılamaktadır (Bakaç ve Sılay, 1999; Oflaz ve Kaya Şengören, 2015). Bu algının fizik derslerinde matematiğin çok kullanılmasından ve konularının işlenmesinde genelde mantk yürütmeyi gerektirmesinden kaynaklandığı söylenebilir (Aycan ve Yumuşak, 2006). Fizik derslerinde yasalarının ifade edilmesinde ve karşılaşılan problemlerin çözümünde matematik bilgisine ihtiyaç duyulmaktadır. Ayrıca, kuram ile uygulama arasında köprü oluşturmada matematik dilinden yararlanmak kaçınılmaz hale gelmektedir (Güzel, 2004). Aycan ve Yumuşak (2006) tarafindan gerçekleştirilen bir araştırmada, bu bilgiyi destekler nitelikte bir bulgu elde edilmiştir. Elde edilen bulgular matematik dersinde başarılı olan öğrencilerin fizik dersinde daha başarılı olduğu, fizik ve matematik derslerinde başarıı olan öğrencilerin fizik tutum puanlarının yüksek olduğunu ortaya koymuştur.

Fizik dersinin öğrenciler üzerinde etkili olabilmesi ve öğretmenin başarılı bir sınıf ortamı oluşturabilmesi için öğrencilerin fizik dersine yönelik tutumlarını olumlu hale getirmek gerekmektedir. Tutum, değişik bilim insanları tarafindan değişik şekilde tanımlanmıştı. Örneğin, Fishbein ve Ajzen (1975) tutumu, verilen bir objeye, istikrarlı bir şekilde ondan yana ya da karşı olmak biçiminde davranma biçiminde öğrenilmiş bir ön eğilim olarak tanımlarken (Leder, 1992), Koballa (1995) tutumu, eşyalara, yerlere, insanlara, durumlara veya fikirlere olumlu ya da olumsuz tepki verme biçiminde tanımlamaktadır. Öğrencilerin fizik dersine ilişkin olumlu duygu ve düşüncelere sahip olması ve fizik dersini sevmesi öğrencinin fizik alanında oluşan olumsuz yaşantılarla baş etme kapasitesine olumlu katkı sağlamakta ve kişinin kendini fizik alanında yetkin olduğu düşüncesine ulaştırmaktadır (Leder, 1992). Tutum sadece öğrenmenin olup olmamasını değil aynı zamanda öğrenme tarzını da etkilemektedir (Atasoy, 2004; Bağçe, Yetişir ve Kaptan, 2006). Kısaca, duygular, amaçlar ve motivasyon öğrencilerin fiziğin doğasına ve öğrenimine ilişkin bakış açısını etkilemekte ve fizik öğretimine nasıl yaklaşacağını belirlemektedir denilebilir.

Fizik dersinin bir diğer amacı da öğrencilerin başarısı üzerinde önemli bir etkiye sahip olan akademik benlik tasarım- 
larını olumlu tutmaktır. Akademik benlik tasarımı ise bir öğrencinin belli bir akademik uğraş karşısında, diğer öğrencilere göre kendisinin ne kadar yetenekli olduğu hakkında geliştirdiği kanısı olarak tanımlanmaktadır (Arseven, 1986). Diğer bir deyişle, akademik benlik tasarımı öğrencinin belli bir öğrenme biriminde ne derece başarılı olacağını, kendini sınıf arkadaşları ile kıyasladığında kendi konumunun ne olacağını ve ilgili dersten elde edeceği başarının kendisi için ne anlam ifade edeceğini ortaya koymaktadır (Pehlivan ve Köseoğlu, 2010). Fizik dersine yönelik akademik benlik tasarımı ise öğrencinin fizik konuları hakkında başarıp başaramayacağına dair kendisini algılaması olarak ele alınmıştı. Ulaşılabilen bazı akademik çalışmalar, akademik benlik tasarımı ile akademik başarı arasında anlamlı ve olumlu yönde bir ilişkinin olduğunu ortaya koymuştur (Çalışkan, Selçuk ve Özcan, 2010; Pehlivan ve Köseoğlu, 2011). Bu nedenle, bu çalışmada, fen lisesi öğrencilerinin fizik dersine ilişkin akademik benlik tasarımları test edilmek istenmiştir.

\section{Çalışmanın Amacı}

Günümüz bilgi ve teknoloji çağıdır ve bundan dolayı bilgi ve teknolojide hızla değişim ve dönüşümlerle karşı karşıya kalmaktayız. Bilgi ve teknolojiyi takip etmede geride kalan toplumlar diğer ülkelere bağımlı hale gelmektedir. Bu da toplumlar ve devletler arasında bir yarışa ve bir rekabete yol açmaktadır. Bilgi ve teknoloji, en çok, sağlıkta, tarımda, iletişimde, endüstride ve eğlence sektöründe değişmekte ve dönüşmektedir. Bu sektörlerin gelişmesinde ve değişmesinde büyük ölçüde fizik kanunlarından ve ilkelerinden yararlanılmaktadır (Wambudu ve Changeiyewo, 2008). Fizik ise çevremizdeki doğal olayların anlaşılmasıyla ilgili deneysel gözlemler ve nicel ölçümlere dayanan temel bir bilim dalıdır (Aycan ve Yumuşak, 2003). Fizik ülkeler ve toplumlar için bu kadar önemli olmakla birlikte öğrenciler tarafından soyut ve anlaşııması zor bir ders olarak algılanmakta, bir çok öğrenci bu dersten başarısız olmakta ve çoğu öğrenci de bu dersi almayı istememektedir (Bakaç ve Sılay, 1999; Oflaz ve Kaya Şengören, 2015; Ergün, 2015; Wambugu ve Changeiywo, 2008; Mekonnen, 2014). Ülkemiz koşulları düşünüldüğünde, bilim ve teknoloji üretmeye yönelik alt eğitim kademesi olarak karşımıza fen liseleri çıkmaktadır. Fen lisesi öğrencilerin temel bir bilim olarak kabul gören fizik dersine yönelik olumlu tutum ile akademik benlik tasarımlarına sahip olmaları hem bireysel anlamda hem de toplumsal anlamda önemli katkılar sağlayacağı düşünülmektedir.

\section{Alt Problemler}

Bu çalışmada, bilim ve teknoloji üretme amacına hizmet etmesi düşünülen fen lisesi öğrencilerinin temel bilim alanlarından biri olan fizik dersine yönelik tutumları ile akademik benlik tasarımları üzerinde çalışıımıştır ve aşağıdaki sorulara yanıt aranmıştr;

- Fen Lisesi öğrencilerinin fizik dersine yönelik tutumları ile akademik benlik tasarımları cinsiyet faktöründen etkilenmekte midir?

- Fen Lisesi öğrencilerinin fizik dersine yönelik tutumları ile akademik benlik tasarımları sınıf düzeyi faktöründen etkilenmekte midir?

- Fen Lisesi öğrencilerinin fizik dersine yönelik tutumları ile akademik benlik tasarımları başarı durumu faktöründen etkilenmekte midir?

- Fen Lisesi öğrencilerinin fizik dersine yönelik tutumları ile akademik benlik tasarımları öğrenim görmeyi planladığı fakülte faktöründen etkilenmekte midir?

\section{Yöntem}

\subsection{Araştırmanın Modeli}

Bu araştırma Ankara Fen Lisesi öğrencilerinin çeşitli değişkenler açısından fizik dersine yönelik tutumları ile akademik benlik tasarımlarını ortaya koymaya yönelik betimsel bir araştırmadır.

\section{2. Çalışma Grubu}

Bu araştırmaya Ankara Fen Lisesi'nde öğrenim gören toplam 339 öğrenci katılmıştr. Bu öğrencilerin 92'si 1. sınıfta, $91^{\prime} i$ 2. sınıfta, $75^{\prime} \mathrm{i}$ 3. sınıfta ve 81'i 4. sınıfta öğrenim görmektedir. Bu öğrencilerin 99'u kız, 240'ı ise erkektir.

\subsection{Veri toplama Araçları}

Bu araştırmada veri toplama aracı olarak bir adet fizik dersine yönelik tutum ölçeği ile akademik benlik tasarımı ölçeği kullanılmıştır. Ölçeklerin özellikleri aşağıda sunulmuştur.

\section{a) Tutum Ölçeği:}

Bu çalışmada öncelikle araştırmacı tarafindan 37 maddelik bir deneme formu oluşturulmuş ve ölçek bu haliyle 
Kırklareli Fen Lisesi öğrencileri üzerinde denenmiştir. Ön uygulama sonucunda işlerliği olmayan üç madde ölçekten çıkarılmıştır. Kırklareli Fen lisesi'nde gerçekleştirilen ön uygulamada ölçeğin alfa güvenirliği 0.95 olarak bulunmuştur. Ankara Fen Lisesi'nde gerçekleştirilen asıl uygulamada ise 34 maddeden oluşan ölçeğin alfa güvenirliği 0.96 olarak bulunmuştur. Araştırma kapsamında kullanılan fizik dersine yönelik tutum ölçeğinden alınabilecek en düşük puan 34, en yüksek puan 170 ve kararsızlık durumunda ise 102'dir

\section{b) Akademik Benlik Tasarımı Ölçeği}

Bu çalışmada Brookover et al (1964) tarafindan geliştirilen ve Senemoğlu (1989) tarafindan Türkçe'ye uyarlanan sekiz maddelik akademik benlik tasarımı ölçeği kullanılmıştı (Pehlivan ve Köseoğlu, 2010). Ölçeğin ön uygulaması Kırklareli Fen Lisesi'nde gerçekleştirilmiş ve ön uygulama sonucundaki alfa güvenirliği 0.80 olarak bulunmuştur. Fizik dersine yönelik "Akademik Benlik tasarımı Ölçeği"nden alınabilecek en düşük puan 8, en yüksek puan 40, kararsızlık durumunda ise 24 'tür.

\subsection{Verilerin Analizi}

Araştırmadan elde edilen veriler bilgisayar ortamına aktarılmış ve SPSS paket programında uygun analizler yapılmıştır. Verilerin analizinde ikili grupların karşılaştırmasında t testi, ikiden fazla grupların karşılaştırması durumunda ise tek yönlü varyans analizinden yararlanılmıştır. Elde edilen F değerinin anlamlı olması halinde Scheffe testi yapılmıştır.

\section{Bulgular ve Yorumu}

\subsection{Birinci Alt Probleme İlişkin Bulgular}

Birinci alt problem " Fen lisesi öğrencilerinin fizik dersine yönelik tutumları ile akademik benlik tasarımları cinsiyet faktöründen etkilenmekte midir?" sorusuna yanıt aranmıştır.

Tablo 1. Fen Lisesi Öğrencilerinin Cinsiyete Göre Fizik Dersine Yönelik Tutum ve Akademik Benlik Tasarımı Puan Ortalama ve standart Sapma ve $t$ Değerleri

\begin{tabular}{llccccc}
\hline & Cinsiyet & $\mathrm{N}$ & $\bar{x}$ & $\mathrm{ss}$ & $\mathrm{t}$ & $\mathrm{p}$ \\
\hline \multirow{2}{*}{ Tutum } & KIz & 99 & 113.74 & 25.19 & \multirow{2}{*}{3.978} & \multirow{2}{*}{$.000^{*}$} \\
& Erkek & 240 & 125.99 & 26.04 & & \multirow{2}{*}{102} \\
\hline \multirow{2}{*}{ ABT } & Kız & 99 & 29.55 & 25.19 & \multirow{2}{*}{1.638} & \multirow{2}{*}{.102} \\
& Erkek & 240 & 30.85 & 30.85 & & \\
\hline
\end{tabular}

Tablo 1'de görüldüğü üzere, kız ve erkek öğrencilerin fizik dersine yönelik tutum puanları arasında 0.01 düzeyinde erkek öğrenciler lehine anlamlı bir farkııık bulunmuştur. Bu tablodan, erkek öğrencilerin fizik dersini daha çok sevdiği ve fizik ile ilgili etkinliklerde bulunmaktan hoşlandıkları sonucuna varılabilir. Tablo 1'de yer alan diğer bir bulguya göre ise, kız ve erkek öğrencilerin fizik dersine yönelik akademik benlik tasarımı ölçeği puanları arasında anlamlı bir fark bulunmamaktadır. Bu bulgu, akademik benlik tasarımı bakımından grupların benzer özellikler sergilediklerini ve kız öğrencilerin de fizik dersini önemsediklerini ortaya koymaktadır.

\section{2. İkinci Alt Probleme illişkin Bulgular}

İkinci alt problemde "Fen lisesi öğrencilerinin fizik dersine yönelik tutumları ile akademik benlik tasarımları sınıf düzeyi faktöründen etkilenmekte midir" sorusuna yanıt aranmıştr.

Tablo 2. Fen Lisesi Öğrencilerinin Sınıf Düzeyine Göre Fizik Dersine Yönelik Tutum ve Akademik Benlik Tasarımı Puan Ortalama ile Standart Sapmaları ve F değerleri

\begin{tabular}{|c|c|c|c|c|c|c|c|c|}
\hline & \multirow{2}{*}{ Sinıf } & \multirow{2}{*}{$\mathrm{N}$} & \multirow{2}{*}{$\bar{x}$} & \multirow{2}{*}{ SS } & \multicolumn{3}{|c|}{ F testi } & \multirow{2}{*}{ Anlamlı Fark } \\
\hline & & & & & sd & $\mathrm{F}$ & $\mathrm{p}$ & \\
\hline \multirow{5}{*}{ Tutum } & 1. Sinıf & 92 & 134.12 & 25.11 & \multirow{5}{*}{3} & \multirow{5}{*}{11.160} & \multirow{5}{*}{.000} & \multirow{5}{*}{$\begin{array}{l}* 1 \text { ve } 2 \text { Sinıf } \\
* 1 \text { ve } 3 \text { Sinıf } \\
* 1 \text { ve } 4 \text { Sinıf }\end{array}$} \\
\hline & 2. Sinıf & 91 & 122.79 & 21.78 & & & & \\
\hline & 3.Sınıf & 75 & 117.67 & 26.31 & & & & \\
\hline & 4.Sinıf & 81 & 113.09 & 27.88 & & & & \\
\hline & Toplam & 339 & 122.42 & 26.36 & & & & \\
\hline
\end{tabular}




\begin{tabular}{|c|c|c|c|c|c|c|c|c|}
\hline & \multirow{2}{*}{ Sinıf } & \multirow[b]{2}{*}{$\mathrm{N}$} & \multirow{2}{*}{$\bar{x}$} & \multirow[b]{2}{*}{ SS } & \multicolumn{3}{|c|}{ F testi } & \multirow{2}{*}{ Anlamlı Fark } \\
\hline & & & & & $s d$ & $\mathrm{~F}$ & $p$ & \\
\hline \multirow{5}{*}{ ABT } & 1. Sinıf & 92 & 32.27 & 5.40 & \multirow{5}{*}{3} & \multirow{5}{*}{3.706} & \multirow{5}{*}{.012} & \multirow{5}{*}{ *1 ve 4 Sinıf } \\
\hline & 2. Sinıf & 91 & 30.31 & 5.44 & & & & \\
\hline & 3. Sinif & 75 & 30.00 & 6.26 & & & & \\
\hline & 4. Sinıf & 81 & 29.04 & 8.85 & & & & \\
\hline & Toplam & 339 & 30.47 & 6.65 & & & & \\
\hline
\end{tabular}

Tablo 2' de yer alan verilerden anlaşılacağı üzere, fizik dersine yönelik tutum bakımından 1. sınıflar ile 2. sınıflar arasında 1. sınıflar lehine, 1. sınıflar ile 3. sınıflar arasında 1. sınıflar lehine ve 1. sınıflar ile 4. sınıflar arasında 1. sınıflar lehine 0.05 düzeyinde anlamlı bir farklılık bulunmaktadır. Bu tablo, 1. sınıf öğrencilerinin fizik dersine yönelik tutum bakımından belirgin bir farklılığa sahip olduklarını ortaya koymaktadır. Yine, Tablo 2, fen lisesi öğrencilerinin fizik dersine yönelik akademik benlik tasarımlarının farklılaştı̆ını ortaya koymaktadır. Farklıık 1. sınıflarla 4. sınıflar arasında 1. sınıflar lehinedir. Bu tablo, 1. sınıf öğrencilerin fizik dersine ilişkin akademik benlik tasarımlarının maksimum düzeyde olduğunu ancak 4. sınıfta belirgin bir düşüş yaşandığını ortaya koymaktadır.

\section{3. Üçüncü Alt Probleme ilişkin Bulgular}

Üçüncü alt problemde "fen lisesi öğrencilerinin fizik dersine yönelik tutumları ile akademik benlik tasarımları başarı düzeyine göre değişmekte midir" sorusuna yanıt aranmıştr.

Tablo 3. Fen Lisesi Öğrencilerinin Başarı Düzeylerine Göre Fizik Dersine Yönelik Tutum ve Akademik Benlik Tasarımı Puan Ortalama ve standart Sapma ve t Değerleri

\begin{tabular}{llccccc}
\hline \multirow{2}{*}{ Değişken } & Başarı & $\mathrm{N}$ & $\bar{x}$ & $\mathrm{Ss}$ & $\mathrm{t}$ & $\mathrm{p}$ \\
\hline \multirow{2}{*}{ Tutum } & İyi & 296 & 123.86 & 25.65 & \multirow{2}{*}{2.680} & \multirow{2}{*}{$.008^{*}$} \\
& Kötü & 43 & 112.44 & 29.33 & & \\
\hline \multirow{2}{*}{ ABT } & İyi & 296 & 31.26 & 6.19 & \multirow{2}{*}{6.015} & $.000^{*}$ \\
& Kötü & 43 & 25.04 & 7.24 & & \\
\hline
\end{tabular}

Tablo 3'te yer alan bulgulara göre, fen lisesi öğrencilerinin fizik dersine yönelik tutumları başarı düzeyinden etkilenmektedir. Başarı düzeyi yüksek öğrencilerin fizik dersine yönelik tutum puanları ile düşük olanların puanları arasında 0.01 düzeyinde başarıı olanlar lehine anlamlı bir fark bulunmaktadır. Yine, Tablo 3'te yer alan bulgulara göre, fen lisesi öğrencilerinin fizik dersine yönelik akademik benlik tasarımları da başarı düzeyinden etkilenmektedirler. Fark 0.01 düzeyinde başarılı öğrenciler lehinedir. Elde edilen sonuç, beklenildiği gibi, akademik başarısı yüksek olan öğrencilerin fizik dersine ilişkin akademik başarı algılamasının da yüksek olduğunu ortaya koymaktadır.

\subsection{Dördüncü Alt Probleme ilişkin Bulgular}

Dördüncü alt problemde " fen lisesi öğrencilerinin fizik dersine yönelik tutumları ile akademik benlik tasarımları öğrenim görmeyi planladıkları fakülteye göre değişmekte midir" sorusuna yanıt aranmıştır.

Tablo 4. Fen Lisesi Öğrencilerinin Öğrenim Görmeyi Planladığı Fakülteye Göre Fizik Dersine Yönelik Tutum ve Akademik Benlik Tasarımı Puan Ortalama ile Standart Sapmaları ve F Değerleri

\begin{tabular}{|c|c|c|c|c|c|c|c|c|}
\hline & \multirow{2}{*}{ Fakülte } & \multirow{2}{*}{$\mathrm{N}$} & \multirow{2}{*}{$\bar{x}$} & \multirow{2}{*}{ Ss } & \multicolumn{3}{|c|}{ F testi } & \multirow{2}{*}{ Anlamlı Fark } \\
\hline & & & & & sd & $\mathrm{F}$ & $P$ & \\
\hline \multirow{4}{*}{ Tutum } & Tip & 155 & 116.68 & 26.65 & \multirow{4}{*}{2} & \multirow{4}{*}{7.886} & \multirow{4}{*}{.000} & \multirow{4}{*}{ *Mühendislik-Tıp } \\
\hline & Mühen. & 147 & 128.49 & 24.66 & & & & \\
\hline & Diğer & 37 & 122.27 & 26.93 & & & & \\
\hline & Toplam & 339 & 122.42 & 26.36 & & & & \\
\hline \multirow{4}{*}{ ABT } & Tıр & 155 & 27.77 & 5.94 & \multirow{4}{*}{2} & \multirow{4}{*}{3.897} & \multirow{4}{*}{.022} & \multirow{4}{*}{$\begin{array}{l}\text { *Mühendislik-Tıp } \\
\text { *Mühendislik-Diğ. }\end{array}$} \\
\hline & Mühen. & 147 & 31.59 & 7.13 & & & & \\
\hline & Diğer & 37 & 29.00 & 7.01 & & & & \\
\hline & Toplam & 339 & 30.47 & 6.65 & & & & \\
\hline
\end{tabular}

Tablo 4' te fen lisesinde öğrenim gören öğrencilerinin fizik dersine yönelik tutumlarının öğrenim görmeyi planladıkları fakülteye göre değiştiğini ortaya koymaktadır. Farklıık 0.01 düzeyindedir ve mühendislik fakültesinde öğrenim 
görmeyi planlayanlar ile tıp fakültesinde öğrenim görmeyi planlayanlar arasında mühendislik fakültesinde öğrenim görmeyi planlayanlar lehinedir. Bu sonuç, mühendis olmayı planlayan öğrencilerin fizik dersine yönelik olumlu bir tutum içinde olduklarını ortaya koymaktadır. Yine Tablo 4'te yer alan bulgular, fen lisesi öğrencilerinin fizik dersine ilişkin akademik benlik tasarımlarının 0.05 düzeyinde farklılaştı̆̆ıı ortaya koymaktadır. Farklılık mühendislik fakültesinde öğrenim görmeyi planlayanlar ile tıp fakültesinde öğrenim görmeyi planlayanlar arasında mühendislik fakültesinde öğrenim görmeyi planlayanlar lehine ve mühendislik fakültesinde öğrenim görmeyi planlayanlar ile diğer fakültelerde öğrenim görmeyi planlayanlar arasında da mühendislik fakültesinde öğrenim görmeyi planlayanlar lehinedir. Bu sonuç, meslek olarak mühendisliğe yönelmek isteyen öğrencilerin fizik dersindeki başarı algısının olumlu olduğunu ortaya koymaktadır.

\section{Sonuç, Tartışma ve Öneriler}

Bu araştırma, fen lisesi öğrencilerinin fizik dersine yönelik tutumları ile akademik benlik tasarımını a) cinsiyet, b) sınıf düzeyi, c) başarı düzeyi ve d) öğrenim görmeyi planladıkları fakülte bazında incelemek amacıyla gerçekleştirilmiştir. Ankara Fen Lisesi’nde öğrenim gören 339 öğrenci üzerinde yürütülen araştırma sonuçlarına göre;

1) Ankara Fen lisesinde öğrenim gören öğrencilerin fizik dersine yönelik tutumları cinsiyete göre farklılık göstermektedir. Farklılık 0.01 düzeyinde erkek öğrenciler lehinedir. Fizik dersine ilişkin akademik benlik tasarımında ise cinsiyetten kaynaklanan bir farklıık elde edilememiştir. Fen lisesi öğrencilerinin fizik dersine yönelik tutumlarında ortaya çıkan farklılık Cannon ve Simpson (1985), Simpson ve Oliver (1985), Woolnough ve Cameron (1991), Weinburgh (1995), George (2000), Demirci (2004), Güzel (2004), Zhu (2007) ve Bang (2013) tarafindan yapılan araştırma bulgularıyla tutarlılık göstermektedir. Bu araştırmadan elde edilen bulgular da erkek öğrencilerin fizik dersine yönelik tutumlarının kız öğrencilerden anlamlı bir şekilde yüksek olduğunu ortaya koymaktadır. Fizik dersinin çok soyut ve karmaşık olması (Bakaç ve Sılay, 1999; Oflaz ve Kaya Şengören, 2015), erkek öğrencilerin soyut konularla daha çok ilgilenmesi, problem çözümü için iyi bir matematik bilgisi gerektirmesi ( Ergün, 2015), iyi bir mantıksal düşünme yeteneği gerektirmesi, erkeklerin iyi bir fizik bilgisi gerektiren mesleklerde kariyer yapmayı planlamaları, ileri düzeyde fizik bilgisine sahip insanların toplumda elit kabul edilmesi, rol model oluşturması bakımında yeterli sayıda ve nitelikte erkek fizikçinin bulunması, kız öğrencilerin fiziğe ilişkin olumsuz tutumlarının olması (Mbaabu, Gatumu ve Kinai, 2011), kız öğrencilerin bu alandan beklentilerinin düşük olması (Özyürek ve Eryılmaz, 2001), kız öğrencilerin daha çok biyoloji gibi, tıp gibi daha insani bilimlere yönelmesi (Hançer, Uludağ ve Yılmaz, 2007) bu farklılıkları desteklemiş olabilir. Akademik benlik tasarımı bakımından cinsiyete ilişkin bir farklılı̆ın çıkmaması ise çevrelerindeki insanlardan (öğretmen, akran, aile vb.) kaynaklanan başarı beklentisi ve seçecekleri mesleğin iyi bir fizik bilgisi gerektirmesi gibi nedenlerle açıklanabilir.

2) Ankara Fen lisesinde öğrenim gören öğrencilerin fizik dersine yönelik tutumları sınıf düzeyine göre değişmektedir. 0.05 düzeyinde tespit edilen farklılık 1.sınıf ile 2. sınıf arasında 1. sınıf lehine, 1. sınıflarla 3. sınıflar arasında 1. sınıflar lehine ve 1. sınıflarla 4. sınıflar arasında 1. sınıflar lehinedir. Ankara Fen lisesinde öğrenim gören öğrencilerin fizik dersine ilişkin akademik benlik tasarımları da değişkenlik göstermektedir. 0.05 düzeyinde tespit edilen farklılık 1 . sınıflar ile 4. sınıflar arasında 1. sınıflar lehinedir. Sınıf düzeyi yükseldikçe, fizik dersine yönelik tutumda düşme olgusu, hem diğer ülkelerde (Kenya, Ermenistan, İrlanda, Ukrayna ve hatta İngiltere, Kanada, Avustralya ve Japonya gibi pek çok endüstrileşmiş ülkede) hem de fen bilimlerinin diğer alanlarında (biyoloji, kimya, matematik gibi) karşımıza bir sorun olarak çıkmaktadır (Baykul, 1999; George, 2000; Gorard ve See, 2009; Pehlivan ve Köseoğlu, 2011; Kaya ve Böyük, 2011). Bu düşüş, öğretmenin niteliğinden, fiziğin güçlüğünden, fiziğin içeriğinden, ileri düzey matematik bilgi, beceri ve başarısı gerektirmesinden, öğrencinin fizik öğrenme yeteneğinden, okul koşullarından kaynaklanabileceği gibi gelecekte seçmeyi düşündükleri meslek ile de bağlantılı olabilmektedir (Uz ve Eryılmaz, 1999). Ayrıca, bu dönemdeki öğrencilerin, gelişimin en zor dönemlerinden olan ergenlik döneminde bulunmaları ve bu dönemde ilginin kendi bedeninde bulunan değişimlere odaklanmış olmaları gibi nedenlerle de duygu, algı, dikkat, bellek, düşünme gibi zihinsel işlevlerin olumsuz etkilenmekte ve derse ilgi, sevgi, derste başarı gibi durumlarda düşme yaşanabilmektedir (Köknel, 1995; Koç, Yavuzer, Demir ve Çalışkan, 2001).

3) Ankara Fen lisesinde öğrenim gören öğrencilerin fizik dersine yönelik tutumları ile akademik benlik tasarımları bakımından 0.01 düzeyinde bir farklılık tespit edilmiştir. Fark başarı düzeyi iyi olanlar lehinedir. Gerek fizik eğitiminde gerekse fen bilimlerinin diğer alanlarında yapılmış olan çalışmalar (Talton ve Simpson, 1986; Uz ve Eryılmaz, 1999; İslim ve Güzel, 2006; Pehlivan ve Köseoğlu, 2011; Pehlivan ve Köseoğlu, 2011; Kaya ve Böyük, 2011) başarı ile tutum arasında ve akademik benlik tasarımı ile akademik başarı arasında (Pehlivan ve Köseoğlu, 2011; Pehlivan ve Köseoğlu, 2011) pozitif yönlü ve olumlu bir ilişki olduğunu ortaya koymaktadır. Tablo 3 incelendiğinde öğrencilerin çok büyük bir bölümünün (\%87) kendini fizik dersinde başarılı bulduğu anlaşılmaktadır. Fen lisesi öğrencilerin özel bir sınavla ve fen ve 
matematik alanında başarılı öğrenciler arasından seçilmeleri, gerekli ön koşul bilgilere sahip olmaları, problem çözme becerilerinin yeterli düzeyde olması, kavram yanılgıları yaşamamaları ve üniversite eğitimi için yapacakları tercihlerin iyi bir matematik ve fizik bilgisi gerektirmesi gibi kişisel sebeplerin yanı sıra öğrencilerin fizik dersini seviyor olmaları, ilgi duyuyor olmaları ve fizikle uğraşmaktan keyif alıyor olmaları gibi duyuşsal sebeplerle fizik dersine önem atfetmeleri mümkündür. Ayrıca, fizik dersinin gerek bireysel olarak kişide bir heyecan uyandırması, gerekse toplumun yaşamını kolaylaştırıcı buluşlar ortaya koymaya uygun olması nedeniyle öğrenciler açısından önemli bir ders olarak algılanmasına neden olmuş olabilir.

4) Ankara Fen lisesinde öğrenim gören öğrencilerin fizik dersine yönelik tutumları ile akademik benlik tasarımları öğrenim görmeyi planladıkları fakülteye göre farklılık göstermektedir. Tutum boyutu ele alındığında, mühendislik fakültesinde öğrenim görmeyi planlayanlar ile tıp fakültesinde öğrenim görmeyi planlayanlar arasında mühendislik fakültesinde öğrenim görmeyi planlayanlar lehine 0.01 düzeyinde anlamlı bir farklılık bulunmaktadır. Akademik benlik tasarımı boyutu incelendiğinde ise mühendislik fakültesinde öğrenim görmeyi planlayanlar ile tıp fakültesinde okumayı planlayanlar arasında mühendislik fakültesinde öğrenim görmeyi planlayanlar lehine ve mühendislik fakültesinde öğrenim görmeyi planlayanlar ile diğer fakültelerde öğrenim görmeyi planlayanlar arasında mühendislik fakültesinde öğrenim görmeyi planlayanlar lehine 0.05 düzeyinde anlamlı bir farklılık görülmektedir. Eryılmaz ve Kırmızı (2002)'nın da belirttiği gibi, fizik tüm mühendisliklerin temelinde vardır ve fiziğe yönelik tutum öğrencilerin geleceğe yönelik amaçları ile kariyer planlarıyla bağlantılı görülmektedir (Uz ve Eryılmaz, 1999; Sneddon, Slaugher ve Reid, 2009; Koç, Yavuzer, Demir ve Çalışkan, 2001).

Elde Edilen sonuçlar doğrultusunda aşağıdaki önerilerde bulunulabilir;

1. Kız öğrencilere de fizik alanında başarılı olma duygusu kazandırılarak ve fizik alanında başarılı olmuş "kadın fizikçi”ler rol model olarak sunularak, onların da hem bilimsel hem de duygusal olarak kazanılmasına çalışılmalıdır.

2. Bilindiği üzere fizik dersi iyi düzeyde matematik bilgisi ve problem çözme becerisine dayanmaktadır. Konuların çoğunlukla soyut ve karmaşık olması bazı öğrencilerin (\%13) kendini başarısız hissetmesine sebep olmaktadır. Bu öğrencileri kazanmak için, bu öğrencilerin anlamada güçlük çektikleri konuları betimleyici çalışmalar ortaya konmalı ve elde edilen sonuçlar eğitim programına yansıtılmalıdır.

3. Öğrencilerin kariyer planları hem fizik dersine yönelik bilişsel çabaları artırdığı için hem de duygusal etmenleri harekete geçirdiği için erken dönemlerde belirlenmesinde ve fizik eğitimi programı bireylerin hedefleri ile bağlantılı olmalıdır.

\section{Kaynaklar}

Arandia,E., Zuza,K ve Guisasola, J. (2016). Attitudes and motivations towards physics and its learning at both high school and university. International Journal of Education and Information Technologies,10, 58-65.

Aslan, A., Ercan, O ve Tekbıyık, A. (2012, Haziran). Fizik dersi yeni öğretim programına ilişkin öğretmen görüşlerinin çeşitli değişkenler açısından değerlendirilmesi. X. Ulusal Fen Bilimleri ve Matematik Kongresi'nde sunulmuş bildiri. Niğde Üniversitesi. Niğde.

Atasoy, B. (2004). Fen Öğrenimi ve Öğretimi. Ankara: Asil Yayınları.

Arseven, D.A. (1986). Çocukta benlik gelişimine ailenin etkisi ve çocuğun okuldaki başarısı. Eğitim ve Bilim. 10, 60, 11-17.

Aycan, Ş ve Yumuşak, A. (2003). Lise fizik müfredatındaki konuların anlaşılma düzeyleri üzerine bir araştırma. Milli Eğitim Dergisi, 159.

Aycan, Ş., Yumuşak, A. (2006, Eylül). Lise 1. sınıf öğrencilerinin fizik ve matematik derslerindeki başarıları ile fiziğe karşı tutumları arasındaki ilişkinin incelenmesi (Demirci Lisesi Örneği). VII. Ulusal Fen Bilimleri ve Matematik Eğitimi Kongresi'nde sunulmuş bildiri. Ankara.

Bağçe, H., Yetişir, İ. ve Kaptan, F. (2006, Eylül). İlköğretim öğrencilerinin fene karşı tutumları ile bilimsel süreç becerile arasındaki ilişki. VII. Ulusal Fen Bilimleri ve Matematik Eğitimi Kongresi'de sunulmuş bildiri. Ankara.

Bakaç, M ve Sılay, İ. (1999). Fizik öğretmen adaylarının yetiştirilmesi sürecinde fizik dersinin amaçlarının rolü üzerine bir araştırma. D.E.Ü Buca Eğitim Fakültesi Dergisi, Özel sayı, 266-270.

Bang, EJ. ve Baker, D.R (2013). Gender differences in Korean high school students' science achievements and attitudes towards science and three different school settings. Mevlana International Journal of Education (MIJE), 3(2), $27-42$.

Baykul, Y. (1990). İlkokul beşinci sınıftan lise ve dengi okulların son sınıflarına kadar matematik ve fen derslerine karşı tutumda görülen değişmeler ve öğrenci seçme sınavındaki başarı ile ilişkili olduğu düşünülen bazı faktörler. Ankara: ÖsYM Yayınları.

Cannon, K.C. ve Simpson, R. D. (1985). Relationship among attitude, motivation, and achievement of ability grouped, seventh-grade, life science students. Science Education, 69,121-138

Çalışkan, S., Selçuk, G.S ve Özcan, Ö.(2010). Fizik öğretmen adaylarının özyeterlik Inançları: Cinsiyet, sınıf düzeyi ve akademik başarının etkileri. Kastamonu Eğitim Dergisi. 18(2), 449-466. 
Demirci, N. (2004). Students' attitudes toward introductory physics course. Hacettepe Üniversitesi Eğitim Fakültesi Dergisi. (26) $33-40$.

Ergün, H. (2015, Eylül). Dönme ve yuvarlanma hareketi ile ilgili üniversite öğrencilerinin yaşadıkları güçlüklerin belirlenmesine yönelik bir araştirma. 2. Ulusal Fizik Eğitimi Kongresi'nde sunulmuş bildiri. Ankara, ODTÜ.

Ertaş, İ. (1993). Denel fizik dersleri. İzmir: Ege Üniversitesi Basımevi.

Eryılmaz, A. ve Kırmızı, S.M. (2002, Eylül). Öğrenci ve öğretmenlerin lise 2 konularını nasıl daha zevkli öğrenebilecekleri hakkında görüşleri. V. Fen Bilimleri ve Matematik Eğitimi Kongresi'nde sunulmuş bildiri. Ankara.

George, R. (2000). Measuring change in students' attitudes toward science over time: An application of latent variable growth modeling. Journal of Science Education and Technology, 9(3), 213-225.

Gorard, S. ve See, B.H. (2009) The Impact of socio-economic status on participation and attainment in science. Studies in Science Education. 45(1), 93-129.

Gök, T. (2006) Fizik eğitiminde işbirlikli öğrenme gruplarında problem çözme stratejilerinin öğrenci başarısı, başarı güdüsü ve tutum üzerindeki etkileri. Yayınlanmamış Doktara tezi. Dokuz Eylül Üniversitesi. İzmir.

Gök, T ve Sılay, İ. (2008a). Fizik öğretiminde işbirlikli öğrenme gruplarında problem çözme stratejilerinin öğrenci başarısı üzerindeki etkileri. Hacettepe Üniversitesi Eğitim Fakültesi Dergisi. (34), 111-126.

Gök, T ve Sılay, İ. (2008b). Effects of problem-solving stratejies teaching on the problem-solving attitudes of cooperative learning groups in physics education. Eğitimde Kuram ve Uygulama. 4 (2), 253-266.

Güzel, H. (2004). The relationship between students' success in physics lessons and their attitudes towards mathematics. Türk Fen Eğitimi Dergisi. 1(1), 28-29.

Hançer, A.H, Uludağ, N ve Yılmaz, A. (2007). Fen Bilgisi öğretmen adaylarının kimya dersine yönelik tutumlarının çeşitli değişkenlere göre değerlendirilmesi. Hacettepe Üniversitesi Eğitim Fakültesi Dergisi, 32,100-109.

İslim, Ü. ve Güzel, H. (2006,Eylül) Öğrencilerin duyuşsal karakteristiklerinin fizik dersi başarısına etkisi. VII. Ulusal Fen Bilimleri ve Matematik Eğitimi Kongresi'nde sunulmuş bildiri. Ankara.

Kaya, H ve Böyük, U. (2011). Attitude towards physics lessons and physicals expriments of the high school students. European J of Physics Education, 2(1), 38-49.

Koballa, T.R. (1988). Attitude and related concepts in science education. Science Education, 72, 115-126.

Koç, M.; Yavuzer, Y.; Demir, Z.; Çalışkan, M.(2001). Gelişim ve öğrenme. Ankara: Nobel yayın Dağıtım.

Köknel, Ö. (1995). Ana-Baba Okulu; Ergenlik Dönemi. İstanbul: Remzi Kitabevi

Leder, G. (1992). Attitudes to mathematics. Mathematics Education Research Journal, 4(3), 1-7.

Mbaabu, F. N., Gatumu, H. N, Kinai, T. (2011). Factorss influencing secondary school students' attitude towards the study of physics in imenti South districk, Kenya. Journal of Research in Education and Society, 2(2), 14-22.

Mirzoyan, J. (2005). History and philosophy of science and secondary physics education in Armenia. http:// www.ihpst2005.leeds.ac.uk/ paper/mirzoyan.pdf (erişim: 12. 10.2009).

Mekonnen, S.(2014). Problems Challenging the Academic Performance of Physics Students in Higher Governmental Institutions in the Case of Arbaminch, Wolayita Sodo, Hawassa and Dilla Universities. Natural Science, 6, 362-375.

Oflaz, O. ve Kaya Şengören, S. (2015, Eylül). Lise öğrencilerinin fizikte görsel okuryazarlık özyeterlikleri. 2. Ulusal Fizik Eğitimi Kongresi'de sunulmuş bildiri. Ankara: ODTÜ.

Özyürek, A ve \& Eryılmaz, A. (2001). Factors affecting student' attitudes towards physics. Eğitim ve Bilim, 26 (120), $21-28$.

Pehlivan, H. ve Köseoğlu, P.(2010). Ankara Fen Lisesi öğrencilerinin biyoloji dersine yönelik tutumları ile akademik benlik tasarımları. Hacettepe Üniversitesi Eğitim Fakültesi Dergisi, 38, 225-235.

Pehlivan, H. ve Köseoğlu, P. (2011). Fen lisesi öğrencilerin kimya dersine yönelik tutumları ile akademik benlik tasarımlarının incelenmesi. Buca Eğitim Fakültesi Dergisi, 29, 90-102.

Pehlivan, H. ve Köseoğlu, P. (2011) Ankara Fen Lisesi öğrencilerinin matematik dersine yönelik tutumları ile akademik benlik tasarımları. Buca Eğitim Fakültesi Dergisi, 31, 153-167.

Seneddon, P.H; Slaughter, K.A ve Reid, N. (2009). Perseptions, wiew and opinions of university students about physics learning during practical work at school. European Journal of Physics. 30, 1119-1129.

Senemoğlu, N.(1989). Öğrenci giriş nitelikleri ve öğretme-öğrenme süreci özelliklerinin Matematik dersindeki öğrenme düzeyini yordama gücü. Yayınlanmamış Araştırma Raporu. Hacettepe Üniversitesi. Ankara.

Simpson, R.D ve Oliver, J.S (1985) Attitude toward science and achievement motivation profiles of male and female science Students in Grades Six Through ten. Secience Education, 69 (4); 511-526.

Talton, E.L. and Simpson, R.D. (1986). "Relationship of attitudes toward self, family, and school with attitude toward science among adolescents."Science Education, 70(4),365-374.

Uz, H. ve Eryılmaz, Ali. (1999). Effects of socioeconomics statüs, locos of control, prior achievement, cumulative GPA, future occupation and achievement in mathematics on students' attitudes towards Physics. Hacettepe Üniversitesi Eğitim Fakültesi. 16-17;105-112. 
Wambugu, P.W \& Changeiywo , J.M. (2008). Effects of mastery learning approach on secondary school students' physics achievement . Eurasia Journal of Mathematics, Science \& Technology Education. 4 (3), 293-302.

Weinburgh, M. (1995). Gender differences in student attitudes toward science: A meta-analysis of the literature from 1970 to 1991. Journal of Research in Science Teaching, 32, 387-398.

Woolnough, J.A \& Cameron, R.S. (1991). Girls, boys and conceptual physics: An evaluation of a senior secondary physics course. Research in Science Education, 21, 377-344.

Zhu, Z. (2007) Learning content, physics self-efficacy, and female students' physics course-taking. International Education Journal, 2007, 8(2), 204-212. 